\title{
Effects of Lactobacillus fermentum HY01 on the quality characteristics and storage stability of yak yogurt
}

\author{
Xin Zhang, ${ }^{1}$ Jiajie Yang, ${ }^{1}$ Chao Zhang, ${ }^{1}$ Houyu Chi, ${ }^{1}$ Chongwei Zhang, ${ }^{1}$ Jingjing Zhang, ${ }^{1}$ Tongtong Li, ${ }^{1}$ \\ Libo Liu, ${ }^{1 *}$ and Aili Li ${ }^{1,2 *}$ \\ ${ }^{1}$ Key Laboratory of Dairy Science, Ministry of Education, College of Food Science, Northeast Agricultural University, Harbin 150030, Heilongjiang, \\ China \\ ${ }^{2}$ Heilongjiang Green Food Research Institute, Harbin 150028, China
}

\section{ABSTRACT}

Lactobacillus fermentum HY01 is a probiotic strain screened from traditional yak yogurt, which can effectively relieve enteritis and constipation. This study aimed to evaluate the effects of HY01 as an adjunct starter on the quality and storage of yak yogurt. A total of 36 main volatile flavor substances were detected in all samples. In particular, more aldehydes, esters, and alcohols were detected in yak yogurt prepared by mixed fermentation of L. fermentum HY01 and starter MY105 (including Streptococcus thermophilus and Lactobacillus delbrueckii ssp. bulgaricus). The rheological results showed that the yak yogurt prepared by mixed fermentation of L. fermentum HY01 and starter MY105 had higher apparent viscosity and lower $\tan \delta$ value compared with compared with traditional yak yogurt, yak yogurt with only $L$. fermentum HY01, and cow yogurt with L. fermentum HY01 and starter MY105. Meanwhile, the conjugated linoleic acid in the yak yogurt prepared by mixed fermentation of $L$. fermentum HY01 and starter was significantly higher than those in the HY01 group or the yogurt starter group alone. After $28 \mathrm{~d}$ of storage at $4^{\circ} \mathrm{C}$, the number of HY01 in the yak yogurt prepared by mixed fermentation of $L$. fermentum HY01 and starter was still higher than $10^{7} \mathrm{cfu} / \mathrm{mL}$, its acidity was lower than $110^{\circ} \mathrm{T}$, and its syneresis was the lowest. The results indicated that $L$. fermentum HY01 could improve the flavor, texture, and storage properties of yak yogurt.

Key words: yak yogurt, L. fermentum HY01, volatiles, rheology, fatty acid profile

\section{INTRODUCTION}

Yak yogurt is one of the traditional dairy products in Northwest China, which is rich in microbial resources;

Received June 11, 2021.

Accepted October 8, 2021.

*Corresponding authors: liboliu@126.com and ailimail@neau.edu.cn among them Limosilactobacillus fermentum, Lacticaseibacillus paracasei, Lactobacillus helveticus, and Lactiplantibacillus plantarum are the dominant strains (Bao et al., 2012; Jiang et al., 2020). These strains not only have a variety of beneficial characteristics, such as antioxidant properties, lowering blood lipids, and preventing defecation (Chen et al., 2014; Suo et al., 2014; Ding et al., 2017), but they also endow yak yogurt with special flavor and high sensory acceptability (Jiang et al., 2020). To a certain extent, it can be seen that the strains in yak yogurt determine the quality and probiotic characteristics of yak yogurt. However, yak yogurt is mainly produced by families, by hand, without fixed strains and established production standards, leading to unstable quality of yogurt and short shelf life, which makes it impossible to realize the large-scale production of yak yogurt (Ao et al., 2012; Phiri et al., 2021).

Through the Key Technology Group for Safety Control and Ferment Development of Traditional Dairy Products on Qinghai-Tibet Plateau (Lhasa, China), our research group used the yogurt starter MY105 to solve the problems of bacteria pollution and poor safety in the natural fermentation process. However, the flavor of yak yogurt fermented by MY105 is much less intense than that of traditional yak yogurt. Probiotics are defined as live microorganisms that, when administered in adequate amounts, can confer beneficial effects on the host (Hill et al., 2014), such as anti-hyperglycemic properties (Grom et al., 2020), bone protection (Lee et al., 2020; Balthazar et al., 2021), and protection against gastroenteritis (Balthazar et al., 2021). To maintain probiotics' beneficial effects, they should be at least $10^{6} \mathrm{cfu} / \mathrm{g}$ viable cells in food products. However, the viability of probiotics in food is affected by the species of probiotics, $\mathrm{pH}$, storage temperature, and product constituents (Khorshidian et al., 2020). Yogurt is often used as a carrier of probiotic food because it is rich in nutrients and has buffering capacity to help probiotics proliferate and tolerate harsh conditions in the gastrointestinal tract (Nyanzi et al., 2021). Previous studies have reported that the application of probiotics 
combined with yogurt starters in milk can not only improve the storage stability of fermented milk but also enhance the flavor of fermented milk and enrich the types of functional fermented milk drinks (Tian et al., 2019; Zhou et al., 2019). Lactobacillus fermentum HY01, which can effectively improve inflammatory bowel disease and constipation, has been screened from traditional yak yogurt (Chen et al., 2017, 2018). In addition, the probiotic has shown good synergistic symbiosis with yogurt starter MY105. Thus, our study further used L. fermentum HY01 in co-culture with starter MY105 to produce yak yogurt and analyzed the effects of probiotics on the unique flavor, product quality, and storage stability of yak yogurt products, aiming to improve the overall processing level of the dairy industry in Tibetan communities.

\section{MATERIALS AND METHODS}

\section{Strain Culture and Reagents}

Lactobacillus fermentum HY01 was supplied by the research group of Southwest University (Chongqing, China). Yogurt starter MY105 (including Streptococcus thermophilus and Lactobacillus delbrueckii ssp. bulgaricus) was provided by Danisco.

Both fresh yak milk (mean $\pm \mathrm{SD}$; protein, $4.0 \% \pm$ $0.3 \%$, wt $/$ wt; fat, $6.9 \% \pm 0.1 \% \mathrm{wt} / \mathrm{wt}$; lactose, $5.5 \%$ $\pm 0.2 \% \mathrm{wt} / \mathrm{wt}$; and total solids $18.0 \% \pm 0.4 \%$, wt $/ \mathrm{wt})$ and traditional yak yogurt were provided by Angbala Farmers and Herdsmen Professional Cooperative in Chengdu County (Yushu Tibetan Autonomous Prefecture, China). Fresh cow milk (protein, $3.1 \% \pm 0.2 \%$, $\mathrm{wt} / \mathrm{wt}$; fat, $4.0 \% \pm 0.1 \%$, wt/wt; lactose, $5.5 \% \pm 0.3 \%$, wt/wt; and total solids, $16.0 \% \pm 0.1 \%$, wt/wt) was provided by Wandashan Ranch (Harbin, China).

\section{Yogurt Preparation}

Yak milk or cow milk was heated to $95^{\circ} \mathrm{C}$ for $5 \mathrm{~min}$ in a water bath (Qualtex, Watson Victor Ltd.). Cooled pasteurized milk was combined with $L$. fermentum HY01 (0.02 g/L) or starter MY105 (0.02 g/L), or both, and then placed in a constant-temperature incubator $\left(40^{\circ} \mathrm{C}\right)$ until $\mathrm{pH}$ was 4.6 to 4.5 . Finally, the products were stored at refrigeration temperature $\left(4 \pm 1^{\circ} \mathrm{C}\right)$ for 28 d. Four types of yogurt were prepared: yak yogurt with MY105 (MY), yak yogurt with L. fermentum HY01 (HY), yak yogurt with the combination of $L$. fermentum HY01 and MY105 (HMY), and cow milk with the combination of L. fermentum HY01 and MY105 (HMM). The traditional yak yogurt sample (TY) was used as control.
The traditional technique for production of yak yogurt is as follows. The milk is boiled for $5 \mathrm{~min}$, cooled to room temperature $\left(25^{\circ} \mathrm{C}\right)$, and then placed in a container. A small amount of previously produced yak yogurt is added to the container as a starter, and the mixture is incubated in a warm location $\left(30^{\circ} \mathrm{C} ; 3-4 \mathrm{~h}\right)$. Then the end product does not deteriorate when stored at room temperature for up to $4 \mathrm{~d}$.

Flavor, rheological, fatty acid, and sensory analyses of samples were carried out on d 1 of storage. In addition, samples were collected every $7 \mathrm{~d}$ during refrigerated storage $(1,7,14,21$, and $28 \mathrm{~d})$ for storage stability analysis.

\section{Profile of Volatile Compounds}

Volatile compounds were extracted as described previously (Dan et al., 2019b), with modifications. Extractions were performed by solid-phase microextraction using 50/30- $\mu \mathrm{m}$ DVB/CAR/PDMS (divinylbenzene/ carboxen/polydimethylsiloxane) fibers (Supelco). Briefly, $15 \mathrm{~g}$ of yogurt sample was transferred into a $20-\mathrm{mL}$ vial. Then, the rotor of a magnetic heated stirrer (Key Laboratory of Dairy Science, Harbin City, China) was put in the vial, which was sealed. The prepared vials were kept at $60^{\circ} \mathrm{C}$ for $10 \mathrm{~min}$ in the thermostatic bath of the magnetic heated stirrer. For sampling, the solidphase microextraction device, filled with quartz fiber, was inserted into the sealed vial containing the samples prepared as described, and the fiber was exposed to the headspace for $60 \mathrm{~min}$ at $45^{\circ} \mathrm{C}$ during headspace equilibration. Then the fiber was withdrawn and inserted into a GC-MS 6890/5973N (Agilent Technologies Inc.) with an elastic capillary vessel column (DB-60 $\mathrm{m} \times$ $0.25 \mathrm{~mm}, 0.25-\mu \mathrm{m}$ film thickness, J\&W Scientific) to analyze the volatile flavor compounds. The GC temperature was initially maintained at $80^{\circ} \mathrm{C}$ for $2 \mathrm{~min}$ and then heated to $230^{\circ} \mathrm{C}$ for $8 \mathrm{~min}$ at a rate of $5^{\circ} \mathrm{C} / \mathrm{min}$. The transfer line temperature was maintained at $250^{\circ} \mathrm{C}$. Helium was used as the carrier gas with a flow rate of $1 \mathrm{~mL} / \mathrm{min}$; no split sampling was used. The mass spectrometry was acquired with a source temperature of $225^{\circ} \mathrm{C}$, under a $70-\mathrm{eV}$ ionization potential. The mass scans ranged from 50 to $500 \mathrm{amu}$. Identification of volatile compounds was achieved by comparing their mass spectrum with a standard spectrum in the National Institute of Standards and Technology (NIST02.L) MS library (https://chemdata.nist.gov/dokuwiki/doku .php?id=chemdata:start). For confirmation, the linear retention index of each compound was calculated according to the method of Condurso et al. (2008) and compared with the linear retention index standards of C8-C40 alkanes (40127-U, Supelco). The relative 
volatile abundance was calculated as follows: chromatographic peak area of the test substances in the sample/ chromatographic peak area of the internal standard $x$ internal standard concentration. The internal standard was 1,2-dichlorobenzene solution.

\section{Rheological Characterization}

The rheological properties of yogurt were characterized by using a rotational rheometer (HR1, TA Instruments), with reference to the description of Costa et al. (2019). The yogurt samples were gently placed in the measuring system and allowed to rest for $10 \mathrm{~min}$ for structure recovery and temperature equilibration at $4^{\circ} \mathrm{C}$. Apparent viscosity of the yogurt samples was measured under conditions of gradually increasing shear rate $\left(0.01-300.0 \mathrm{~s}^{-1}\right)$. Frequency sweeps $\left(4 \pm 1^{\circ} \mathrm{C}\right.$, $0.01-100 \%$ strain, $1 \mathrm{~Hz}$ ) were carried out on the yogurt, and the elasticity modulus $\left(\mathbf{G}^{\prime}\right)$ and viscous modulus $\left(\mathbf{G}^{\prime \prime}\right)$ were obtained using a controlled stress VT6 Plus rheometer (Haake rheometer, Thermo Fisher Scientific Inc.) in a suitable program. The tangent of the phase angle was determined according to Equation [1]:

$$
\tan \delta=\frac{\mathrm{G}^{\prime \prime}}{\mathrm{G}^{\prime}}
$$

\section{Fatty Acid Profile}

The fatty acid profiles of the yogurt samples were analyzed by GC-MS (6890N/5973N, Agilent Technologies Inc.) according to the method described by Ajmal et al. (2019). Briefly, the total lipids of the samples were extracted using a chloroform:methanol (2:1) mixture. Then, $30 \mu \mathrm{L}$ of extracted lipid was placed in a 10$\mathrm{mL}$ centrifuge tube, and $2 \mathrm{~mL}$ of hexane and benzene mixed reagent (1:1) was added and gently shaken to dissolve. Then, $2 \mathrm{~mL}$ of $0.5 \mathrm{~mol} / \mathrm{L}$ potassium hydroxide-methanol solution was added, and the mixture was shaken. After standing at room temperature for $30 \mathrm{~min}$, distilled water was added to make all of the organic phase methanol solution rise to the top of the tube. Finally, the supernatant was extracted after standing for $10 \mathrm{~min}$, for further analysis. Extracted samples were analyzed by GC-MS (6890/5973N, Agilent Technologies Inc.) using a DB5 capillary column $(60 \mathrm{~m} \times 0.25$ $\mathrm{mm}, 0.25-\mu \mathrm{m}$ film thickness, J\&W Scientific). The GC temperature was initially maintained at $150^{\circ} \mathrm{C}$ for $2 \mathrm{~min}$ and then heated to $250^{\circ} \mathrm{C}$ for $10 \mathrm{~min}$ at a rate of $5^{\circ} \mathrm{C} /$ min. The transfer line temperature was maintained at $250^{\circ} \mathrm{C}$. Helium was used as the carrier gas, with a flow rate of $1 \mathrm{~mL} / \mathrm{min}$. Mass spectra were acquired with a source temperature of $225^{\circ} \mathrm{C}$, under a $70-\mathrm{eV}$ ionization potential. The mass scans ranged from 50 to $500 \mathrm{amu}$.
Individual fatty acids in the samples were identified and quantified by comparing their retention and peak areas with their respective standards (37-component FAME mix, ANPEL). Data were expressed as the percentage (\% wt/wt) of total FAME. The proportion of CLA isomers (cis-9,trans-11 and trans-10,cis-12) in the samples was determined using the procedure described by Gutierrez-Pena et al. (2021). All analyses were carried out in quintuplicate. Atherogenic index [ATI; $(\mathrm{C} 12: 0+4 \times 14: 0+\mathrm{C} 16: 0) /(\mathrm{MUFA}+\mathrm{PUFA})]$ and thrombogenic index [TI; $(\mathrm{C} 14: 0+\mathrm{C} 16: 0+\mathrm{C} 18: 0) /$ $(0.5 \times$ MUFA $+0.5 \times \mathrm{n}-6+3 \times \mathrm{n}-3+\mathrm{n}-3 / \mathrm{n}-6)]$ were computed using the procedure proposed by Chalabi et al. (2018).

\section{Viable Cell Counts}

After $72 \mathrm{~h}$ of aerobic incubation at $37^{\circ} \mathrm{C}$, the bacterial counts of L. fermentum and L. bulgaricus were recorded on De Man, Rogosa, and Sharpe (MRS)-maltose (pH 6.2) and MRS agar ( $\mathrm{pH} 4.58)$, respectively. The colony characteristics of L. fermentum and L. bulgaricus are smooth, round, and white, and not smooth, cottonshaped, light white, respectively. Bacterial counts of Strep. thermophilus were determined on M17 medium (pH 7.0; Hope Bio).

\section{Physicochemical and Syneresis Determinations}

The $\mathrm{pH}$ of the yogurt samples was determined using a digital $\mathrm{pH}$ meter (Mettler Toledo), and the acidity of the yogurts was measured by titration with $0.1 \mathrm{~mol} / \mathrm{L}$ $\mathrm{NaOH}$ with phenolphthalein as an indicator, according to the method of Huang et al. (2020). The syneresis of yogurt was determined according to the method of Moreno-Montoro et al. (2018). Twenty grams of yogurt was placed in a funnel with filter paper at $4^{\circ} \mathrm{C}$ for $2 \mathrm{~h}$, and the whey was collected and weighed. Syneresis was expressed as the percentage of weight of whey collected over the initial weight of the yogurt.

\section{Sensory Analysis}

The sensory properties of yogurts (yogurt samples were served chilled) were evaluated by a trained panel of 20 judges: 10 men and 10 women, aged between 20 and 30 yr. Judges had 5 trainings under the supervision of experts to assess the sensory attributes of yogurt (the ambient temperature during the sensory test was $25^{\circ} \mathrm{C}$, and the temperature of the yogurt sample was $4^{\circ} \mathrm{C}$ ). Each assessor was given sheets with a 9-point scale for each characteristic (color, mouthfeel, appearance, and taste), according to the methodology described by Heydari et al. (2018): 1 = "very poor," and 9 = "excellent." 


\section{Statistical Analysis}

Experimental data were expressed as the mean \pm standard deviation. Statistical analyses between groups were performed by means of ANOVA $(P<0.05)$. SPSS version 22 (IBM Corp.) was used for the analysis. Covariance matrix and varimax rotation were used for principal component analysis, to analyze the repeatability of samples within the group and the difference between groups. The concentrations of volatile components (total aldehydes, alcohols, ketones, acids, esters, and hydrocarbons) in 5 yogurt samples were used as variables. The principal component analysis and rheological data collection were performed using the Origin 2018 for Windows statistical software package (OriginLab Co.).

\section{RESULTS AND DISCUSSION}

\section{Characterization of Volatile Compounds in Different Yogurts}

A total of 36 volatile flavor substances were detected from 5 groups of yogurt samples, including 10 acids, 6 ketones, 5 esters, 3 aldehydes, 4 alcohols, and 8 hydrocarbons (Table 1). The principal component analysis (Figure 1a) showed that that the HMM group was highly correlated with ketones and hydrocarbons, the HY and the MY groups were highly correlated with acidic volatile substances, and the main volatile substances in the HMY group and the TY groups were aldehydes, esters, and alcohols. A heat map can reflect the similarity and differences among volatile components in different yogurt samples by color gradient and similarity. As shown in Figure 1b, significant differences in volatile flavor compounds occurred between the cow yogurt group (HMM group) and the 4 yak yogurt groups. In the yak yogurt groups, the HY group and the MY group were closer to one another, and the HMY group was more similar to the TY group.

Further analysis showed that the contents and types of acidic volatile components (except 2-propenoic acid and 3-methylbutanoic acid) in the yak yogurt group were significantly higher than those in the cow yogurt group (HMM group), which might be related to the higher fat content in yak milk. Zhao et al. (2018) also found that full-fat yogurt contained more acidic compounds than low-fat yogurt. In addition, the main volatile acids in the yak yogurt groups were hexanoic acid, butyric acid, and acetic acid, and the content of hexanoic acid was highest. Hu et al. (2011) also reported that the traditional Tibetan yak fermented milk contained high hexanoic acid content, which was the main sour component. Furthermore, acetic acid was found in the yogurt of the HY, HMM, and HMY groups but not in the yogurt of the MY group, suggesting that HY01 could promote the production of acetic acid.

The aldehydes highly correlated with the HMY and TY groups were nonanal and 3-methyl-2-butenal (Figure 1b). Fang et al. (2020) analyzed the volatile flavor components of traditional fermented yak milk in different regions of the Qinghai-Tibetan plateau, and found that the main aldehyde substances were nonanal and 3-methyl-2-butenal. However, acetaldehyde was not detected in all yogurt groups. This result was consistent with the report of $\mathrm{Li}$ et al. (2013) and might be related to the fact that acetaldehyde is an unstable compound that is transformed easily into alcohols or corresponding acids. Routray and Mishra (2011) reported that although the acetaldehyde content in yogurts was low, they still presented typical yogurt aroma, suggesting that yogurt aroma was the result of the combination of several aromatic compounds.

The ester substances with high correlation with the HMY and TY groups were isopropyl octanoate, ethyl hexanoate, and ethyl acetate (Figure 1b). These esters had fruity and floral flavors, which could reduce the sharpness and bitterness caused by fatty acids and amines (Cheng, 2010). In addition, ethyl butyrate was detected in yogurt of the HY, HMM, and HMY groups, suggesting that HY01 could promote the production of ethyl butyrate. Jiang et al. (2020) also found that the lactic acid bacteria in yak yogurt could promote the production of ester substances.

The content of 2-ethyl hexanol was higher in the yogurt of the HMY and TY groups than in the other groups (Figure 1b). Alcohols are commonly detected in fermented milk containing yeast or lactic acid bacteria. For example, Huang et al. (2020) found that goat yogurt co-fermented by Kluyveromyces marxianus and yogurt starter contained more alcohol compounds than goat yogurt made with yogurt starter. Dan et al. (2019a) also found a variety of alcohols in milk fermented with $L$. plantarum P-8 and yogurt strains in different ratios. Although low concentration of alcohol had no obvious effect on the flavor of fermented milk, a certain concentration of alcohol could contribute to the mellow flavor.

In addition, the ketone that was highly correlated with the HMM group was diacetyl, whereas the TY, HMY, and MY groups contained only acetoin, with no diacetyl detected. Similarly, Jiang et al. (2020) did not detect diacetyl in yak yogurt, presumably because diacetyl was unstable in a high-pH environment and was easily reduced to acetoin. The yogurt of the HMY and TY groups also contained more 2-heptanone, one of the main ketones in Tibetan fermented yak milk, with fruit and milk sweet flavors (Hu et al., 2011). 
Table 1. Relative abundance of volatile compounds ( $\mu \mathrm{g} / \mathrm{L})$ present in different yogurts $(\mathrm{n}=5$, mean $\pm \mathrm{SD})$

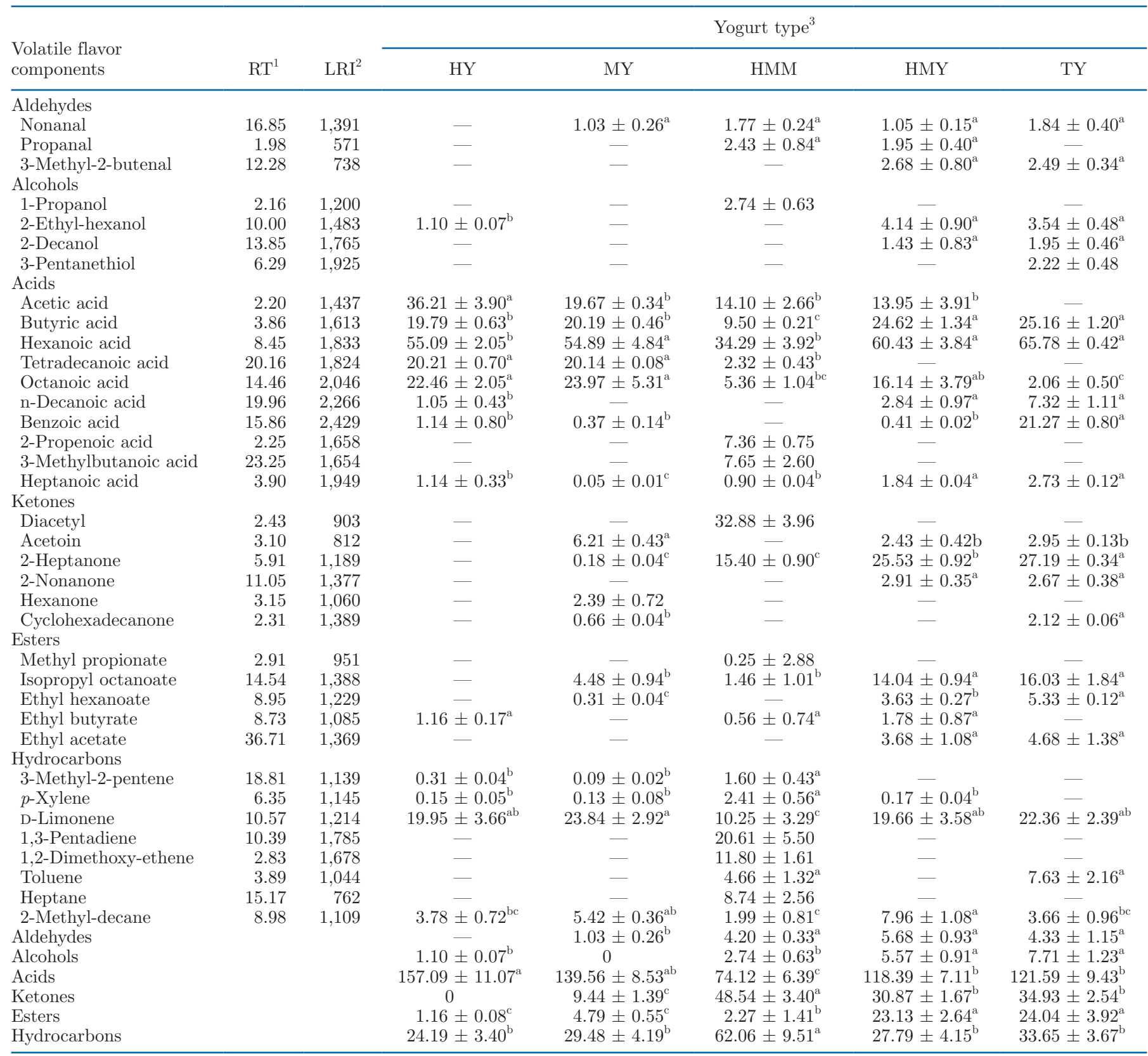

$\overline{\mathrm{a}-\mathrm{d}}$ Means within a row with different superscript letters differ significantly $(P<0.05)$.

${ }^{1}$ Retention time.

${ }^{2}$ Linear retention index.

${ }^{3} \mathrm{HY}=$ yak yogurt with Lactobacillus fermentum HY01; MY = yak yogurt with starter MY105 (including Streptococcus thermophilus and Lactobacillus delbrueckii ssp. bulgaricus); HMM = cow yogurt with MY105 and HY01; HMY = yak yogurt with MY105 and HY01; and TY = traditional yak yogurt.

\section{Rheological Properties of Yogurt}

As shown in Figure 2a, the apparent viscosity of all samples decreased with the increase of shear rate, showing pseudoplastic behavior. In the entire shear rate range, the viscosity of the yak yogurt groups was higher than that of the HMM group. This might be due to yak milk being rich in fat, which acts as a filler between casein micelles, improving the apparent viscosity of yogurt (Rodríguez et al., 2015). Nguyen et al. (2014) reported that the viscosity of milk fermented by Lactobacillus acidophilus increased with increasing milk fat 
a

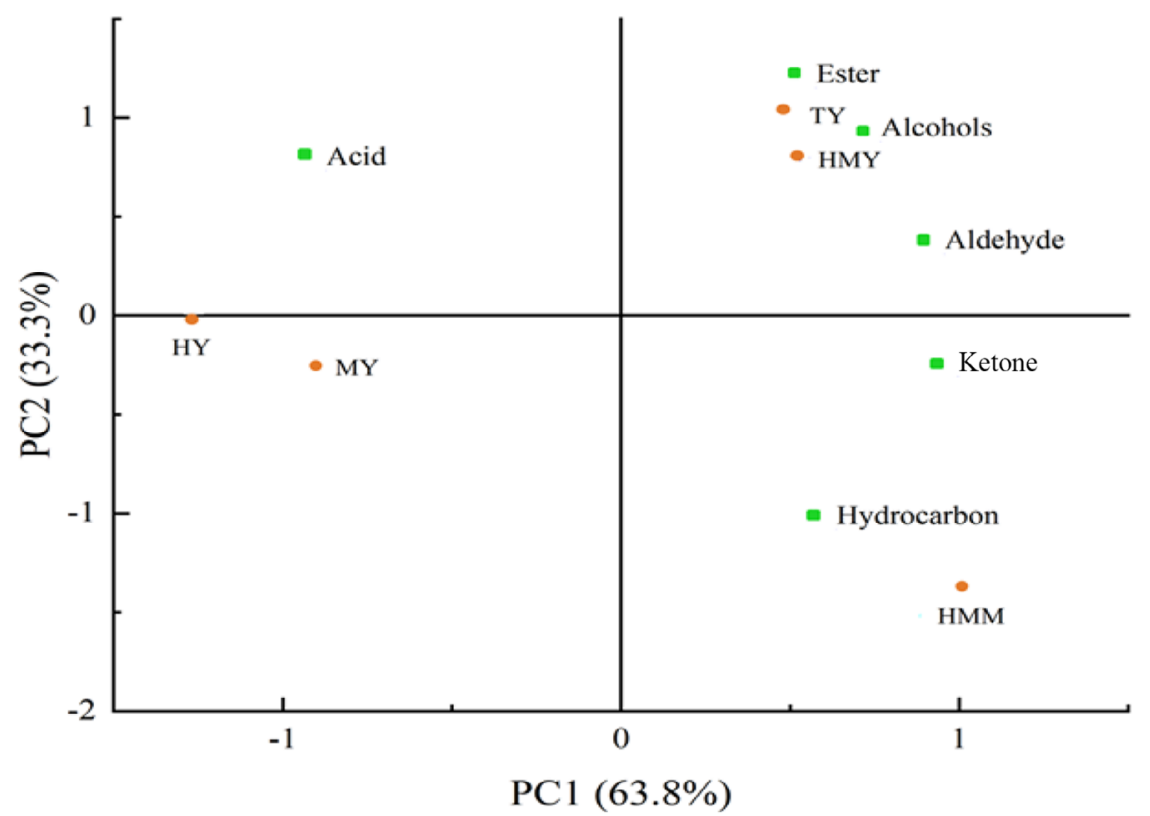

$\mathrm{b}$

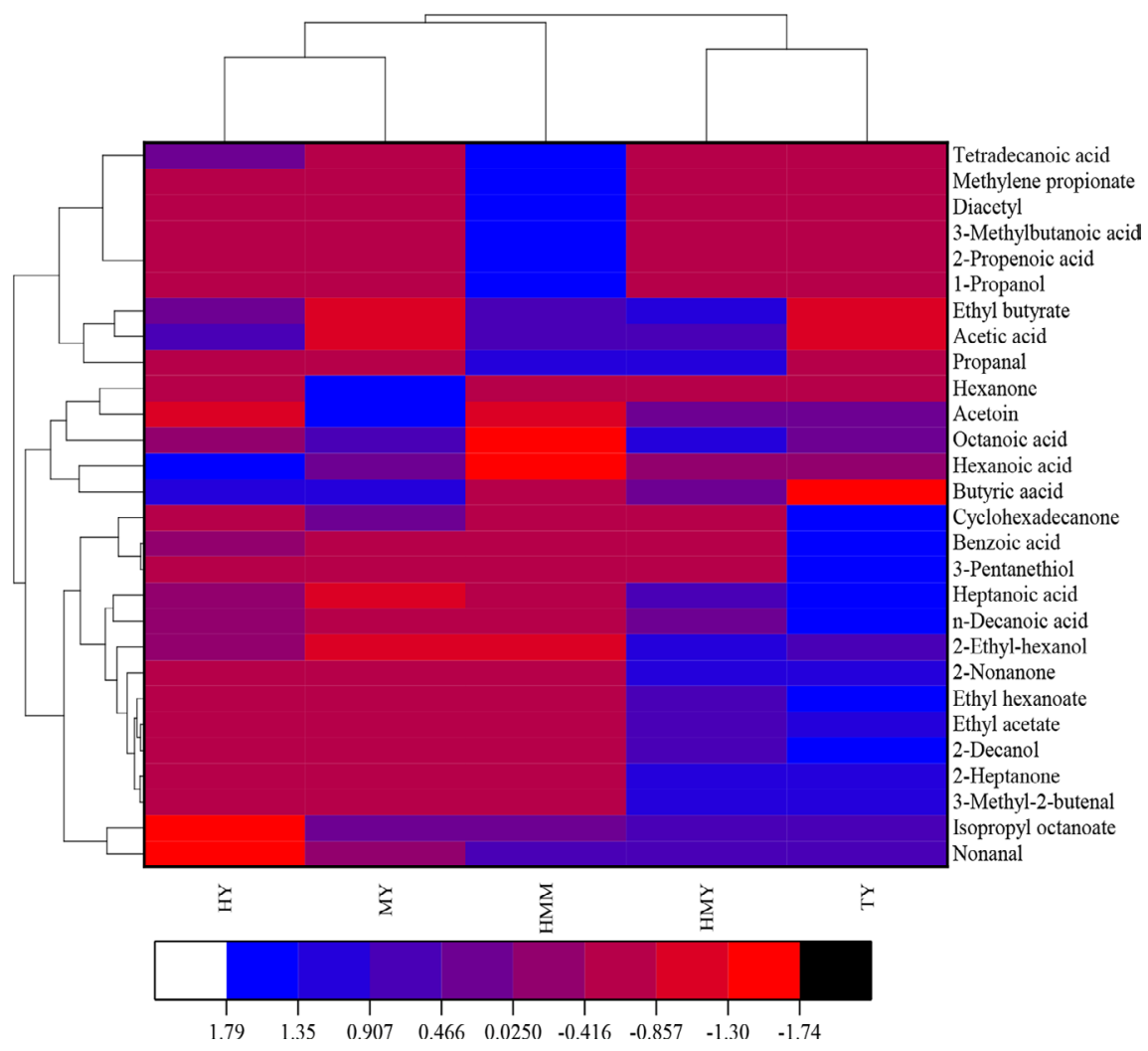

Figure 1. (a) Loading plot and score plot from principal component analysis of different yogurts. PC = principal components. Green squares and orange circles represent different yogurts and flavor compounds, respectively. (b) Heat map and clustering of the selected main volatile compounds for TY, MY, HY, HMY, and HMM. TY = traditional yak yogurt; MY = yak yogurt with starter MY105 (including Streptococcus thermophilus and Lactobacillus delbrueckii ssp. bulgaricus); HY = yak yogurt with Lactobacillus fermentum HY01; HMY = yak yogurt with MY105 and HY01; HMM = cow yogurt with MY105 and HY01. 
a

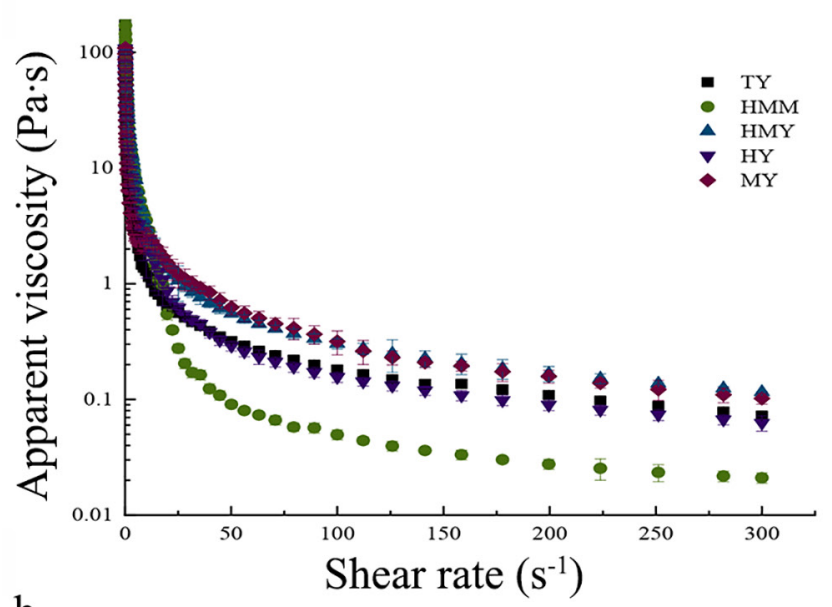

b

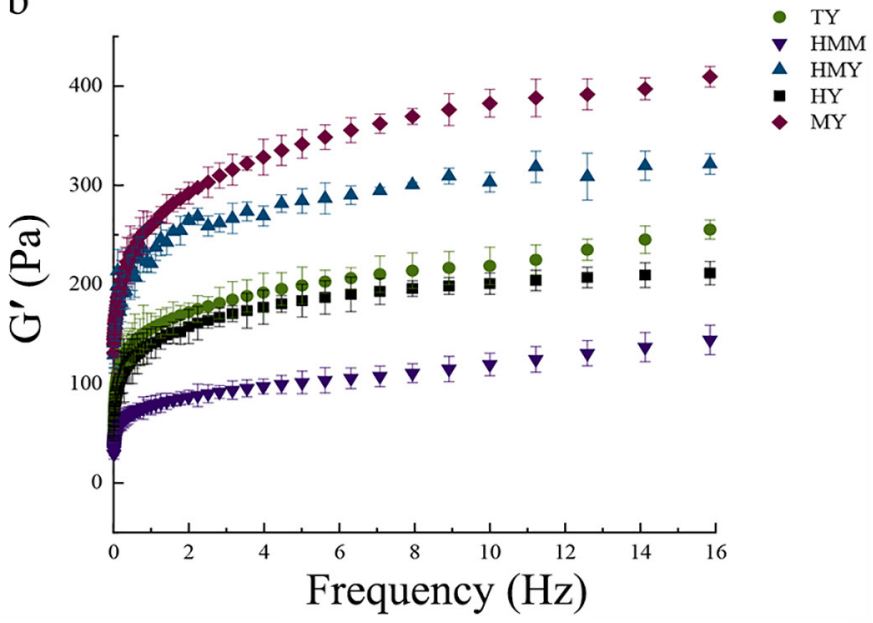

$\mathrm{C}$

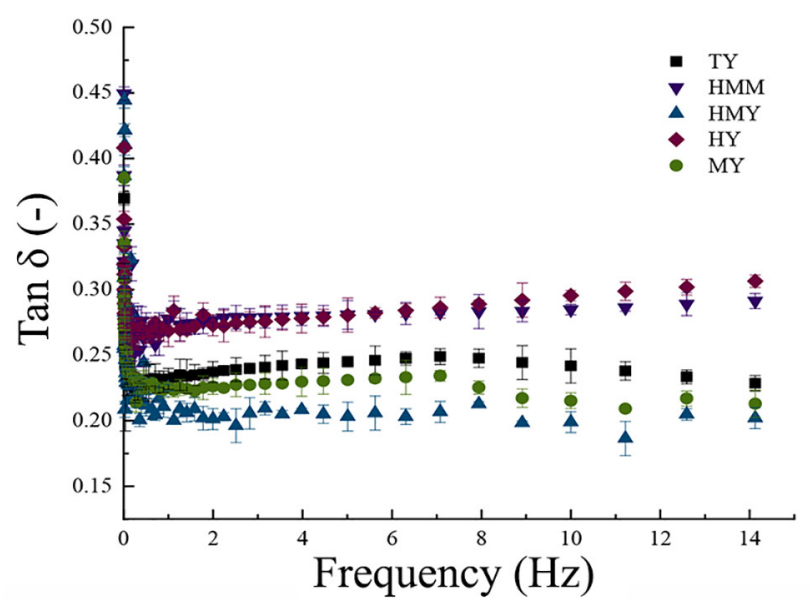

Figure 2. Apparent viscosity (a), elastic modulus $\left(\mathrm{G}^{\prime}, \mathrm{b}\right)$, and tangent of the phase angle $(\operatorname{Tan} \delta, \mathrm{c})$ of yak yogurts or cow yogurt. $\mathrm{TY}=$ traditional yak yogurt; $\mathrm{MY}=$ yak yogurt with starter MY105 (including Streptococcus thermophilus and Lactobacillus delbrueckii ssp. bulgaricus); HY = yak yogurt with Lactobacillus fermentum HY01; HMY = yak yogurt with MY105 and HY01; HMM = cow yogurt with MY105 and HY01. $\mathrm{N}=5$. Error bars represent SD. content. In addition, the viscosity of the HMY group, fermented by mixed bacteria, was higher than that of that HY and MY groups. However, the viscosity of TY group yogurt was significantly lower than that of the HMY group, which might be due to its low $\mathrm{pH}(<4)$, which was not conducive to the growth and metabolism of lactic acid bacteria (Kaditzky and Vogel, 2008; Li et al., 2021).

The elastic modulus $\left(\mathrm{G}^{\prime}\right)$ of all yogurts increased in a frequency-dependent manner (Figure $2 \mathrm{~b}$ ). The $\mathrm{G}^{\prime}$ value of the yak yogurt group was higher than that of the HMM group, indicating that yak yogurt, with high protein content, had stronger viscoelasticity than yogurt made with cow milk. Similarly, Marafon et al. (2011) observed that protein-rich yogurt had a higher $\mathrm{G}^{\prime}$ compared with low-protein milk. Among the yak yogurts, the MY group had the highest $\mathrm{G}^{\prime}$ value, followed by the HMY, TY, and HY groups. Nguyen et al. (2014) found that a fast acidification rate (meaning a low $\mathrm{pH}$ value) resulted in a short action time of protein particles, and fewer casein micelles were associated with a low $\mathrm{G}^{\prime}$ of yogurt

The solid properties of yogurt are very important for consumers' acceptance of the product; ideal yak yogurt should be viscous, consistent, and creamy. As shown in Figure 2c, the $\tan \delta$ value of the yak yogurt group was lower than that of the HMM group, and the $\tan \delta$ value of the HMY group was below 0.2 , which was lower than that of the TY, MY, and HY groups, indicating that its protein network structure was good, that the yogurt had a low molecular mobility, and that the product had solid-like characteristics.

\section{Fatty Acid Profiles of the 5 Yogurts}

Dairy products with a high content of short-chain fatty acids (SCFA, C4:0 to C10:0) are more easily absorbed by the body (Albenzio et al., 2013). The content of SCFA in yak yogurt, especially butyric acid (C4:0) and hexanoic acid (C6:0), was significantly higher $(P$ $<0.05$ ) than that of cow yogurt (Table 2). Cui et al. (2016) reported that yak milk had a higher content of SCFA compared with cow milk. Batool et al. (2018) also confirmed that buffalo milk contained more SCFA than cow milk, resulting in significantly higher SCFA in buffalo Cheddar cheese than in cow Cheddar cheese. In addition, the content of SCFA in the HMY group was close to that of the TY group, and was significantly higher $(P<0.05)$ than those of the HY and MY groups. This may be related to their mixed fermentation. For example, Jia et al. (2016) reported that co-fermentation with yogurt starter promoted lipolysis activity of Lactobacillus rhamnosus GG, resulting in more SCFA 
in goat yogurt. Santillo et al. (2009) also observed that C4:0 and C6:0 concentrations in Pecorino cheese prepared with mixed bacteria (including L. acidophilus,
Bifidobacterium lactis, and Bifidobacterium longum) were higher than those in Pecorino cheese prepared using L. acidophilus alone.

Table 2. Fatty acid content $(\mathrm{mg} / \mathrm{g})$ and fatty acid profile of yak yogurts or cow yogurt $(\mathrm{n}=5$, mean $\pm \mathrm{SD})$

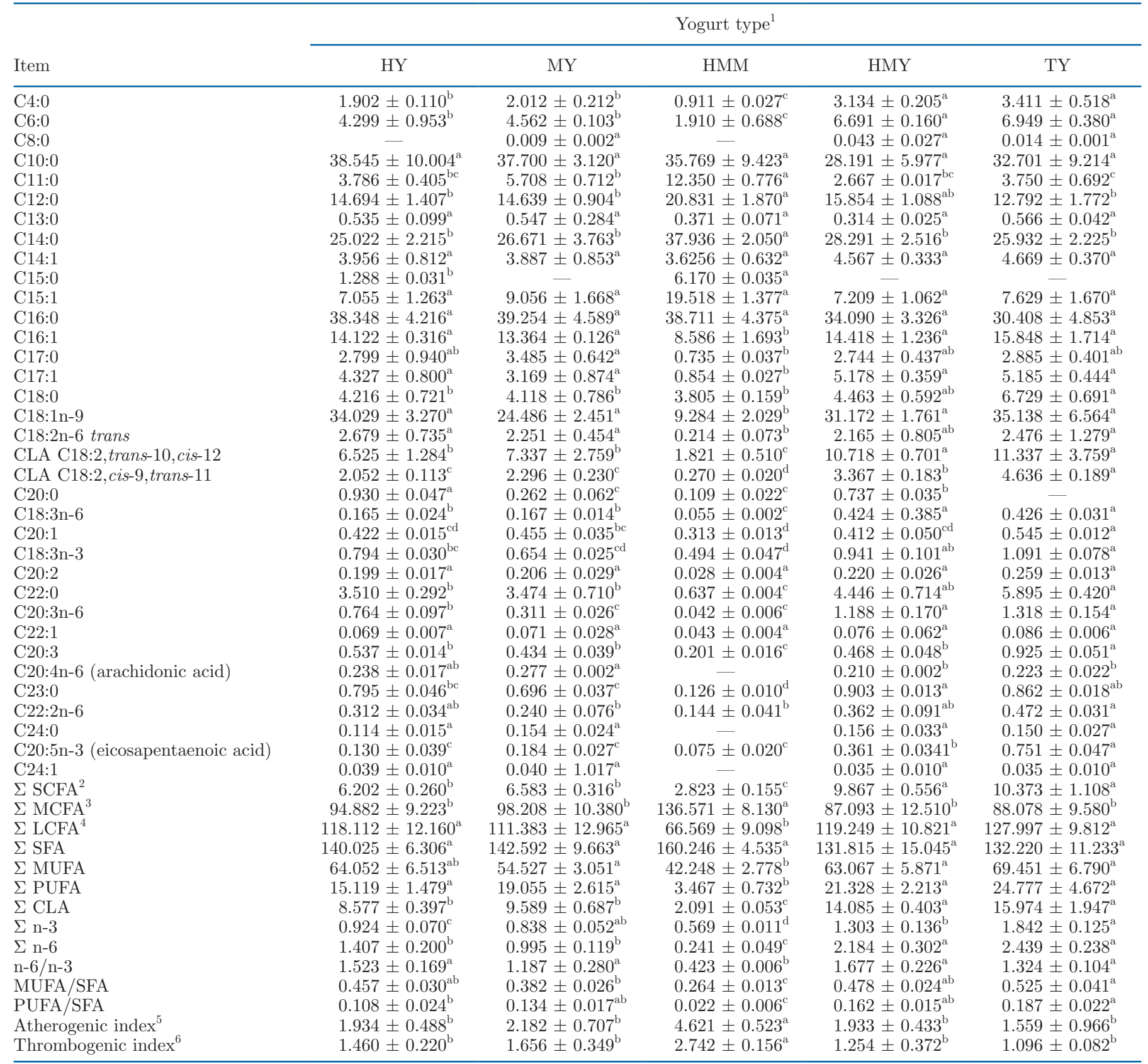

${ }^{\mathrm{a}-\mathrm{d}}$ Means within a row with different superscript letters differ significantly $(P<0.05)$.

${ }^{1} \mathrm{TY}=$ traditional yak yogurt; HMY = yak yogurt with MY105 and HY01; MY = yak yogurt with starter MY105 (including Streptococcus thermophilus and Lactobacillus delbrueckii ssp. bulgaricus); HY = yak yogurt with Lactobacillus fermentum HY01; HMM = cow yogurt with MY105 and HY01.

${ }^{2}$ Short-chain fatty acids $(\mathrm{C} 4-\mathrm{C} 10)$.

${ }^{3}$ Medium-chain fatty acids (C12-C15:1).

${ }^{4}$ Long-chain fatty acids (C 16:0-C 24:0).

${ }^{5}(\mathrm{C} 12: 0+4 \times 14: 0+\mathrm{C} 16: 0) /(\mathrm{MUFA}+\mathrm{PUFA})$.

${ }^{6}(\mathrm{C} 14: 0+\mathrm{C} 16: 0+\mathrm{C} 18: 0) /(0.5 \times$ MUFA $+0.5 \times \mathrm{n}-6+3 \times \mathrm{n}-3+\mathrm{n}-3 / \mathrm{n}-6)$. 
Excessive intake of medium-chain fatty acids (MCFA, C12-C15:1), especially C14:0, may increase total cholesterol levels and risk of cardiovascular disease (Lopez-Huertas, 2010). As shown in Table 2, the content of MCFA in yak yogurt was significantly lower $(P<0.05)$ than that of cow yogurt. Consistent with our research, Or-Rashid et al. (2008) found that the content of MCFA in yak cheese was significantly lower than in ordinary cheese, which was speculated to be related to the lower MCFA content in yak milk. In addition, the MCFA content of our 4 types of yak yogurts ranged from 87.093 to $98.208 \mathrm{mg} / \mathrm{g}$, with no significant difference $(P>0.05)$. Güler and Gürsoy-Balcı (2011) also reported that adding different proportions of starter CH-1 (Strep. thermophilus) and starter YF-3331 ( $L$. delbrueckii ssp. bulgaricus) had no effect on the content of MCFA in goat yogurt.

The main long-chain fatty acids (C16:0-C24:0) in the yogurt samples (Table 2) were palmitic acid (C16:0), stearic acid (C18:0), oleic acid (C18:1 n-9) and CLA (C18:2 cis-9,trans-11 and C18:2 trans-10,cis-12). The contents of oleic acid and CLA in yak yogurt were significantly higher $(P<0.05)$ than in cow yogurt. Similarly, Guo et al. (2014) observed that the contents of oleic acid and CLA in yak milk, butter, and cheese were twice those of cow dairy products. Conjugated linoleic acid is one of the most important long-chain fatty acids. It not only has anti-tumor, anti-oxidation, and anti-atherosclerosis properties, but also can improve the relative density of bones, reduce body fat accumulation, and regulate the immune system (Belury, 2002). The CLA content in the HMY group (14.085 \pm 0.403 $\mathrm{mg} / \mathrm{g})$ was significantly higher $(P<0.05)$ than that of the MY $(9.589 \pm 0.687 \mathrm{mg} / \mathrm{g})$ and HY groups $(8.577$ $\pm 0.397 \mathrm{mg} / \mathrm{g})$, but showed no significant difference from the TY group $(15.974 \pm 1.947 \mathrm{mg} / \mathrm{g})$. Oleic acid can be used as a substrate for the production of CLA. For example, Sieber et al. (2004) pointed out that $L$. fermentum ATCC 14931, Bifidobacterium, and Propionibacterium in yogurt could convert linoleic acid into CLA. Co-cultivation of probiotics with starter or yeast can also increase the content of CLA in fermented milk. Oliveira et al. (2009) found that co-fermentation of $L$. acidophilus and Strep. thermophilus could increase the CLA content in yogurt. El Galiou et al. (2015) observed that traditional homemade fresh goat cheeses rich in microorganisms contained a large amount of CLA.

In addition, ATI and TI are related health indicators to evaluate fatty acids. In this experiment, the ATI and TI indexes of yak yogurt were significantly lower than those of the HMM group $(P<0.05)$, which might be related to the yak rearing environment. Gutiérrez-Peña et al. (2021) reported that cheese made from sheep milk produced by fresh-forage sheep could significantly reduce saturated fatty acids, ATI, and TI in cheese. Interestingly, we found no significant difference in ATI and TI between the TY, HMY, MY, and HY yogurt groups. Muelas et al. (2018) also observed no significant difference in the ATI and TI of goat fermented milk fermented by different probiotics or commercial starters (commercial mixed culture MA400).

\section{Sensory Properties of 5 Yogurts}

Temporal dominance of sensations, temporal checkall-that-apply, and preferred attribute elicitation can measure the sensory quality of products over time and characterize consumers' acceptance of functional yogurt (Wu et al., 2019; Costa et al., 2020). Figure 3 shows that the TY group had the highest flavor score but poor mouthfeel. The flavor and mouthfeel of the HY, MY, and HMM groups were not ideal. Both the acceptability and mouthfeel of the HMY group were the highest, suggesting that HMY yogurt was most popular with consumers. The sensory scores were consistent with the results of the flavor and rheological property analyses of yogurt.

\section{Viable Counts and Physicochemical Changes of Yogurts During Storage}

The survival ability of probiotics during product storage determines the health benefits of fermented products. The viable bacteria counts of HY01 in the HMY group remained at $10^{8} \mathrm{cfu} / \mathrm{mL}$ in the first 14 $\mathrm{d}$ and decreased to $10^{7} \mathrm{cfu} / \mathrm{mL}$ after $14 \mathrm{~d}$ (Table 3 ). During the storage period, the counts of viable HY01 bacteria in the HMY group and the HY group were significantly higher $(P<0.05)$ than in the HMM group. The possible reason may be that HY01 was more suitable for growing in yak milk. We also observed that the numbers of yogurt starters (L. bulgaricus, Strep. thermophilus) remained above $10^{7} \mathrm{cfu} / \mathrm{mL}$ during the 28-d storage period, and no significant difference occurred between the different groups. Dimitrellou et al. (2019) reported that different raw milks (such as cow milk vs. goat milk) had no effect on the number of yogurt starters during storage.

Consistent with the change of bacteria count, the titrated acidity of yak yogurt during storage was higher than that of cow yogurt (Figure 4a, b). In particular, the TY group had the lowest $\mathrm{pH}$ value (3.81) and the highest titration acidity $\left(136.1^{\circ} \mathrm{T}\right)$. This might be related to the co-fermentation of lactic acid bacteria and yeast in TY yogurt. Huang et al. (2020) reported that goat yogurt fermented with lactic acid bacteria and 


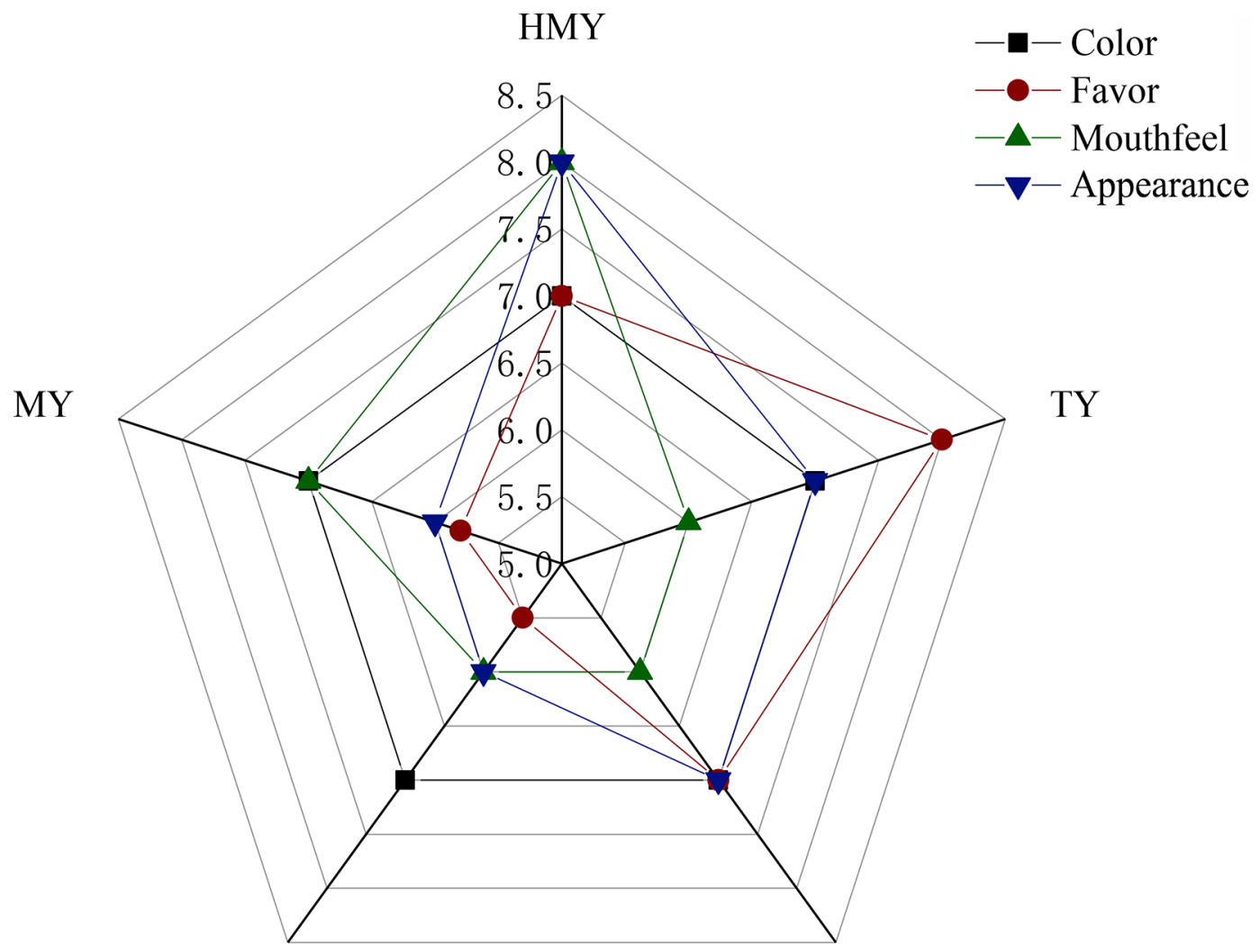

HY

HMM

Figure 3. Sensory evaluation of yogurt samples at the end of ripening. TY = traditional yak yogurt; MY = yak yogurt with starter MY105 (including Streptococcus thermophilus and Lactobacillus delbrueckii ssp. bulgaricus); HY = yak yogurt with Lactobacillus fermentum HY01; HMY = yak yogurt with MY105 and HY01; HMM = cow yogurt with MY105 and HY01.

Table 3. Viability of microorganisms $\left(\log _{10} \mathrm{cfu} / \mathrm{mL}\right)$ used in yogurt production during refrigerated storage $(\mathrm{n}=3$, mean $\pm \mathrm{SD})$

\begin{tabular}{|c|c|c|c|c|c|}
\hline Microorganism & $\begin{array}{l}\text { Time } \\
\text { (d) }\end{array}$ & \multicolumn{4}{|c|}{ Yogurt type $^{1}$} \\
\hline Lactobacillus fermentum HY01 & $\begin{array}{l}1 \\
7 \\
14 \\
21 \\
28\end{array}$ & $\begin{array}{l}8.43 \pm 0.10^{\mathrm{A}, \mathrm{b}} \\
8.09 \pm 0.12^{\mathrm{AB}, \mathrm{b}} \\
7.67 \pm 0.27^{\mathrm{BC}, \mathrm{b}} \\
7.28 \pm 0.13^{\mathrm{C}, \mathrm{c}} \\
6.84 \pm 0.05^{\mathrm{D}, \mathrm{c}}\end{array}$ & $\begin{array}{l}8.90 \pm 0.08^{\mathrm{A}, \mathrm{a}} \\
8.83 \pm 0.08^{\mathrm{A}, \mathrm{a}} \\
8.52 \pm 0.17^{\mathrm{A}, \mathrm{a}} \\
7.95 \pm 0.15^{\mathrm{B}, \mathrm{a}} \\
7.71 \pm 0.07^{\mathrm{B}, \mathrm{a}}\end{array}$ & $\begin{array}{l}8.85 \pm 0.11^{\mathrm{A}, \mathrm{ab}} \\
8.75 \pm 0.2^{\mathrm{A}, \mathrm{a}} \\
8.26 \pm 0.05^{\mathrm{B}, \mathrm{ab}} \\
7.73 \pm 0.11^{\mathrm{C}, \mathrm{b}} \\
7.36 \pm 0.08^{\mathrm{CA}, \mathrm{b}}\end{array}$ & $\begin{array}{l}- \\
- \\
- \\
-\end{array}$ \\
\hline Lactobacillus delbrueckii ssp. bulgaricus & $\begin{array}{l}1 \\
7 \\
14 \\
21 \\
28\end{array}$ & $\begin{array}{l}8.77 \pm 0.06^{\mathrm{A}, \mathrm{a}} \\
8.58 \pm 0.10^{\mathrm{A}, \mathrm{a}} \\
8.12 \pm 0.09^{\mathrm{B}, \mathrm{a}} \\
7.66 \pm 0.04^{\mathrm{C}, \mathrm{a}} \\
7.44 \pm 0.05^{\mathrm{C}, \mathrm{a}}\end{array}$ & $\begin{array}{l}8.83 \pm 0.05^{\mathrm{A}, \mathrm{a}} \\
8.73 \pm 0.04^{\mathrm{A}, \mathrm{a}} \\
8.32 \pm 0.02^{\mathrm{B}, \mathrm{a}} \\
7.81 \pm 0.07^{\mathrm{C}, \mathrm{a}} \\
7.62 \pm 0.08^{\mathrm{CD}, \mathrm{a}}\end{array}$ & $\begin{array}{l}- \\
- \\
-\end{array}$ & $\begin{array}{l}8.61 \pm 0.05^{\mathrm{A}, \mathrm{a}} \\
8.51 \pm 0.07^{\mathrm{A}, \mathrm{a}} \\
8.28 \pm 0.10^{\mathrm{B,a}} \\
7.72 \pm 0.15^{\mathrm{BC}, \mathrm{a}} \\
7.39 \pm 0.07^{\mathrm{C}, \mathrm{a}}\end{array}$ \\
\hline
\end{tabular}

${ }^{\mathrm{a}-\mathrm{d}}$ Means within a row with different lowercase superscript letters differ significantly $(P<0.05)$.

${ }^{\mathrm{A}-\mathrm{D}}$ Means within a column with different uppercase superscript letters differ significantly $(P<0.05)$.

${ }^{1} \mathrm{HMM}=$ cow yogurt with MY105 and HY01; HMY = yak yogurt with MY105 and HY01; HY = yak yogurt with Lactobacillus fermentum HY01; MY = yak yogurt with starter MY105 (including Streptococcus thermophilus and Lactobacillus delbrueckii ssp. bulgaricus). 
yeast had a lower $\mathrm{pH}$ value than that fermented by bacteria alone. In addition, the titration acidity of our HMY group slowly decreased from 14 to $28 \mathrm{~d}$, whereas the titration acidity value of the HY group continued to decrease during storage, resulting in the titration acidity value of the HY group being significantly higher than that of the HMY group. Dan et al. (2019a) also found that co-fermentation of L. plantarum and starter could reduce post-acidification of yogurt and improve the stability of products during storage. Acceptable $\mathrm{pH}$ and total acidity ranges for consumers are 4.0 to 4.4 and 70 to $110^{\circ} \mathrm{T}$, respectively. Therefore, the HMY group exhibited more suitable acidity value and storage stability.

As shown in Figure 4c, the syneresis value of our 4 groups of yak yogurt was significantly lower than that of the HMM group. This might be because yak milk had a higher total solid content, improving the gel strength of the yogurt and reducing the pore size, thereby locking in more water and reducing syneresis (Moreno-Montoro et al., 2018). In addition, compared with the HY and MY groups, the syneresis value of the HMY group was smaller, suggesting that the viscosity and gel strength of yogurt prepared using mixed bacteria during storage were better than those with added HY01 or yogurt starter alone. Mahmood et al. (2019) also confirmed the syneresis value of yogurt prepared with an L. acidophilus LA06FT complex starter was low.

\section{CONCLUSIONS}

This study evaluated the effect of L. fermentum HY01 as an adjunct starter on the quality and storage characteristics of yak yogurt. In co-fermentation with traditional starters, HY01 improved the texture of yak yogurt and increased the abundance of volatile flavor compounds, especially nonanal, 3-methyl-2-butenal, isopropyl octanoate, ethyl hexanoate, ethyl acetate, and 2-ethyl hexanol. The addition of HY01 also promoted the production of short-chain and long-chain fatty acids, such as C4:0, C6:0, and CLA. Meanwhile, yak yogurt was a good carrier for HY01, and the quantity of HY01 was still higher than $10^{7} \mathrm{cfu} / \mathrm{mL}$ after storage at $4^{\circ} \mathrm{C}$ for $28 \mathrm{~d}$. It can be seen that HY01 has good potential for use in the production of functional yak dairy products.

\section{ACKNOWLEDGMENTS}

This study was supported by the National Key Research and Development Plan (grant number 2018YFD0502404; Lhasa, China). The authors have not stated any conflicts of interest.
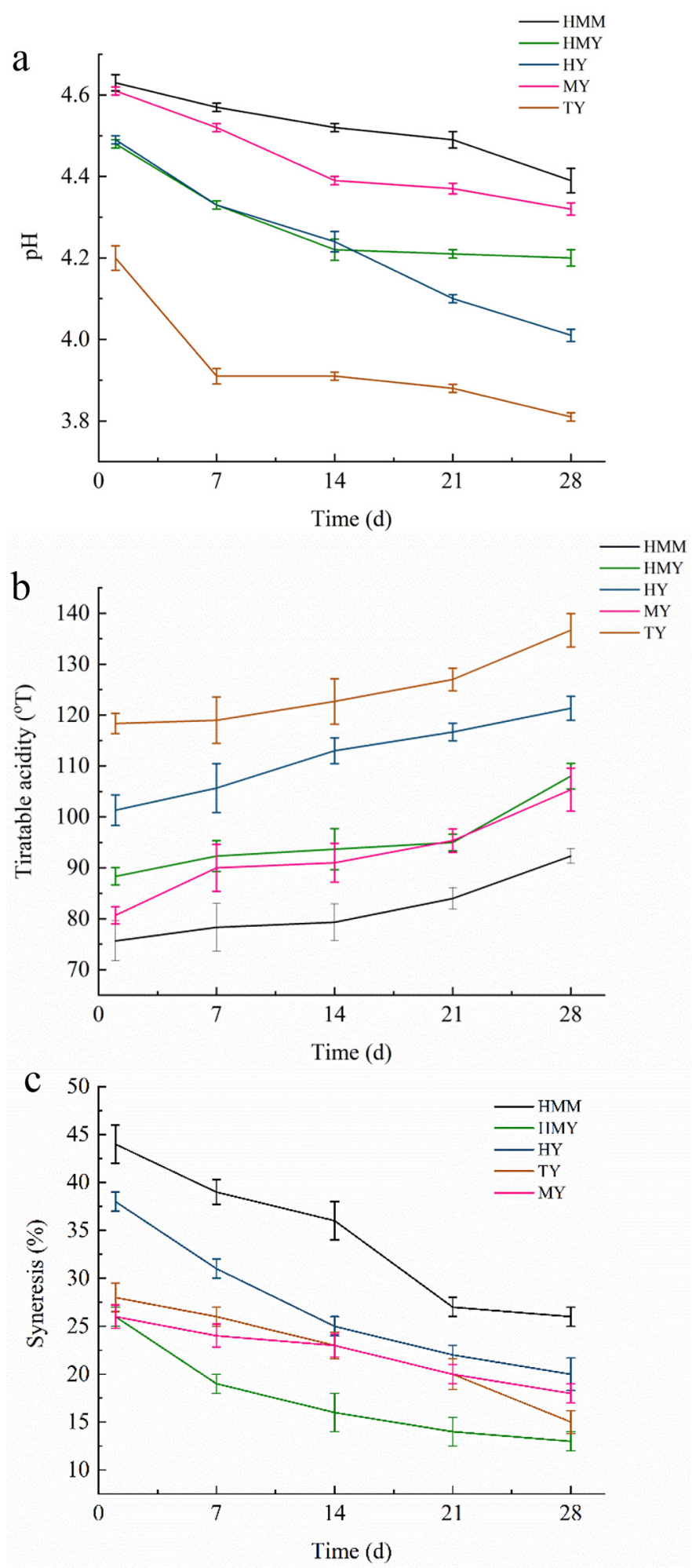

Figure 4. Mean ( $\pm \mathrm{SD}$ ) values of $\mathrm{pH}(\mathrm{a})$, titratable acidity (b), and syneresis (c) of yogurts during storage at $4^{\circ} \mathrm{C}$ for up to $28 \mathrm{~d}$. TY = traditional yak yogurt; MY = yak yogurt with starter MY105 (including Streptococcus thermophilus and Lactobacillus delbrueckii ssp. bulgaricus); $\mathrm{HY}=$ yak yogurt with Lactobacillus fermentum HY01; HMY = yak yogurt with MY105 and HY01; HMM = cow yogurt with MY105 and HY. 


\section{REFERENCES}

Ajmal, M., M. Nadeem, M. Imran, Z. Mushtaq, M. H. Ahmad, M. Tayyab, M. K. Khan, and N. Gulzar. 2019. Changes in fatty acids composition, antioxidant potential and induction period of UHTtreated tea whitener, milk and dairy drink. Lipids Health Dis. 18:213. https://doi.org/10.1186/s12944-019-1161-x.

Albenzio, M., A. Santillo, M. Caroprese, D. Ruggieri, F. Napolitano, and A. Sevi. 2013. Physicochemical properties of Scamorza ewe milk cheese manufactured with different probiotic cultures. J. Dairy Sci. 96:2781-2791. https://doi.org/10.3168/jds.2012-6218.

Ao, X., X. Zhang, X. Zhang, L. Shi, K. Zhao, J. Yu, L. Dong, Y. Cao, and Y. Cai. 2012. Identification of lactic acid bacteria in traditional fermented yak milk and evaluation of their application in fermented milk products. J. Dairy Sci. 95:1073-1084. https://doi .org/10.3168/jds.2011-4224.

Balthazar, C. F., N. A. de Moura, G. R. Romualdo, R. S. Rocha, T. C. Pimentel, E. A. Esmerino, M. Q. Freitas, A. Santillo, M. C. Silva, L. F. Barbisan, A. G. Cruz, and M. Albenzio. 2021. Synbiotic sheep milk ice cream reduces chemically induced mouse colon carcinogenesis. J. Dairy Sci. 104:7406-7414. https://doi.org/10.3168/ jds.2020-19979.

Bao, Q. H., W. J. Liu, J. Yu, W. H. Wang, M. J. Qing, X. Chen, F. Wang, J. C. Zhang, W. Y. Zhang, J. M. Qiao, T. S. Sun, and H. P. Zhang. 2012. Isolation and identification of cultivable lactic acid bacteria in traditional yak milk products of Gansu Province in China. J. Gen. Appl. Microbiol. 58:95-105. https://doi.org/10 .2323 /jgam.58.95.

Batool, M., M. Nadeem, M. Imran, I. T. Khan, J. A. Bhatti, and M. Ayaz. 2018. Lipolysis and antioxidant properties of cow and buffalo cheddar cheese in accelerated ripening. Lipids Health Dis. 17:228. https://doi.org/10.1186/s12944-018-0871-9.

Belury, M. A. 2002. Dietary conjugated linoleic acid in health: Physiological effects and mechanisms of action. Annu. Rev. Nutr. 22:505531. https://doi.org/10.1146/annurev.nutr.22.021302.121842.

Chalabi, M., G. Bahrami, and A. Mostafaie. 2018. Kermanshahi roghan and yoghurt: Comparison of fatty acid profiles and lipid qualities. Int. J. Dairy Technol. 71:1-5.

Chen, X., J.-L. Song, Q. Hu, H. Wang, X. Zhao, and H. Suo. 2018. Positive enhancement of Lactobacillus fermentum HY01 on intestinal movements of mice having constipation. Appl Biol Chem. 61:39-48. https://doi.org/10.1007/s13765-017-0327-3.

Chen, X., X. Zhao, H. Wang, Z. Yang, J. Li, and H. Suo. 2017. Prevent effects of Lactobacillus fermentum HY01 on dextran sulfate sodium-induced colitis in mice. Nutrients 9:545. https://doi.org/ $10.3390 /$ nu9060545.

Chen, Y., W. Liu, J. Xue, J. Yang, X. Chen, Y. Shao, L. Y. Kwok, M. Bilige, L. Mang, and H. Zhang. 2014. Angiotensin-converting enzyme inhibitory activity of Lactobacillus helveticus strains from traditional fermented dairy foods and antihypertensive effect of fermented milk of strain H9. J. Dairy Sci. 97:6680-6692. https:// doi.org/10.3168/jds.2014-7962.

Cheng, H. 2010. Volatile flavor compounds in yogurt: A review. Crit. Rev. Food Sci. Nutr. 50:938-950. https://doi.org/10.1080/ 10408390903044081.

Condurso, C., A. Verzera, V. Romeo, M. Ziino, and F. Conte. 2008. Solid-phase microextraction and gas chromatography mass spectrometry analysis of dairy product volatiles for the determination of shelf-life. Int. Dairy J. 18:819-825. https://doi.org/10.1016/j .idairyj.2007.12.005.

Costa, G. M., M. M. Paula, G. N. Costa, E. A. Esmerino, R. Silva, M. Q. Freitas, C. E. Barão, A. G. Cruz, and T. C. Pimentel. 2020. Preferred attribute elicitation methodology compared to conventional descriptive analysis: A study using probiotic yogurt sweetened with xylitol and added with prebiotic components. J. Sens. Stud. 35:1-9. https://doi.org/10.1111/joss.12602.

Costa, M. F., T. C. Pimentel, J. T. Guimaraes, C. F. Balthazar, R. S. Rocha, R. N. Cavalcanti, E. A. Esmerino, M. Q. Freitas, R. S. L. Raices, M. C. Silva, and A. G. Cruz. 2019. Impact of prebiotics on the rheological characteristics and volatile compounds of Greek yogurt. Lebensm. Wiss. Technol. 105:371-376. https://doi.org/10 $.1016 / j . l w t .2019 .02 .007$

Cui, G. X., F. Yuan, A. A. Degen, S. M. Liu, J. W. Zhou, Z. H. Shang, L. M. Ding, J. D. Mi, X. H. Wei, and R. J. Long. 2016. Composition of the milk of yaks raised at different altitudes on the QinghaiTibetan Plateau. Int. Dairy J. 59:29-35. https://doi.org/10.1016/ j.idairyj.2016.02.046.

Dan, T., H. Chen, T. Li, J. Tian, W. Ren, H. Zhang, and T. Sun. 2019a. Influence of Lactobacillus plantarum P-8 on fermented milk flavor and storage stability. Front. Microbiol. 9:3133.

Dan, T., W. Ren, Y. Liu, J. Tian, H. Chen, T. Li, and W. Liu. 2019b. Volatile flavor compounds profile and fermentation characteristics of milk fermented by Lactobacillus delbrueckii ssp. bulgaricus. Front. Microbiol. 10:2183. https://doi.org/10.3389/fmicb.2019 .02183 .

Dimitrellou, D., C. Salamoura, A. Kontogianni, D. Katsipi, P. Kandylis, G. Zakynthinos, and T. Varzakas. 2019. Effect of milk type on the microbiological, physicochemical and sensory characteristics of probiotic fermented milk. Microorganisms 7:274. https://doi.org/ 10.3390/microorganisms7090274.

Ding, W., L. Wang, J. Zhang, W. Ke, J. Zhou, J. Zhu, X. Guo, and R. Long. 2017. Characterization of antioxidant properties of lactic acid bacteria isolated from spontaneously fermented yak milk in the Tibetan Plateau. J. Funct. Foods 35:481-488. https://doi.org/ 10.1016/j.jff.2017.06.008.

El Galiou, O., S. Zantar, M. Bakkali, A. Laglaoui, J. A. Centeno, and J. Carballo. 2015. Chemical and microbiological characteristics of traditional homemade fresh goat cheeses from Northern Morocco. Small Rumin. Res. 129:108-113. https://doi.org/10.1016/j .smallrumres.2015.06.005.

Fang, X., L. W. Guo, H. Chen, W. C. Ke, W. Guo, X. S. Guo, and Y. Zhang. 2020. Characteristics of volatile flavor components in traditional fermented yak milk produced in different ecoregions of the Qinghai-Tibetan plateau. J. Dairy Sci. 103:191-200. https:// doi.org/10.3168/jds.2019-17312.

Grom, L. C., R. S. Rocha, C. F. Balthazar, J. T. Guimaraes, N. M. Coutinho, C. P. Barros, T. C. Pimentel, E. L. Venancio, I. Collopy Jr., P. M. C. Maciel, P. H. F. Silva, D. Granato, M. Q. Freitas, E. A. Esmerino, M. C. Silva, and A. G. Cruz. 2020. Postprandial glycemia in healthy subjects: Which probiotic dairy food is more adequate? J. Dairy Sci. 103:1110-1119. https://doi.org/10.3168/ jds.2019-17401.

Güler, Z., and A. C. Gürsoy-Balcı. 2011. Evaluation of volatile compounds and free fatty acids in set types yogurts made of ewes' goats' milk and their mixture using two different commercial starter cultures during refrigerated storage. Food Chem. 127:10651071. https://doi.org/10.1016/j.foodchem.2011.01.090.

Guo, X., R. Long, M. Kreuzer, L. Ding, Z. Shang, Y. Zhang, Y. Yang, and G. Cui. 2014. Importance of functional ingredients in yak milk-derived food on health of Tibetan nomads living under highaltitude stress: A review. Crit. Rev. Food Sci. Nutr. 54:292-302. https://doi.org/10.1080/10408398.2011.584134.

Gutiérrez-Peña, R., C. Avilés, H. Galán-Soldevilla, O. Polvillo, and M. Delgado-Pertíez. 2021. Physicochemical composition, antioxidant status, fatty acid profile, and volatile compounds of milk and fresh and ripened ewes' cheese from a sustainable part-time grazing system. Foods 10:1-18.

Heydari, S., A. Amiri-Rigi, M. R. Ehsani, M. A. Mohammadifar, N. Khorshidian, M. R. Koushki, and A. M. Mortazavian. 2018. Rheological behaviour, sensory properties and syneresis of probiotic yoghurt supplemented with various prebiotics. Int. J. Dairy Technol. 71:175-184. https://doi.org/10.1111/1471-0307.12491.

Hill, C., F. Guarner, G. Reid, G. R. Gibson, D. J. Merenstein, B. Pot, L. Morelli, R. B. Canani, H. J. Flint, S. Salminen, P. C. Calder, and M. E. Sanders. 2014. The International Scientific Association for Probiotics and Prebiotics consensus statement on the scope and appropriate use of the term probiotic. Nat. Rev. Gastroenterol. Hepatol. 11:506-514. https://doi.org/10.1038/nrgastro.2014 .66 .

Hu, S., H. Wei, S. Guo, L. Li, and Y. Hou. 2011. Flavor evaluation of yak butter in Tsinghai-Tibet Plateau and isolation of microor- 
ganisms contributing flavor. Anim. Sci. J. 82:122-126. https://doi .org/10.1111/j.1740-0929.2010.00803.x.

Huang, Z., L. Huang, G. Xing, X. Xu, C. Tu, and M. Dong. 2020. Effect of co-fermentation with lactic acid bacteria and K. marxianus on physicochemical and sensory properties of goat milk. Foods 9:299. https://doi.org/10.3390/foods9030299.

Jia, R., H. Chen, H. Chen, and W. Ding. 2016. Effects of fermentation with Lactobacillus rhamnosus GG on product quality and fatty acids of goat milk yogurt. J. Dairy Sci. 99:221-227. https://doi .org/10.3168/jds.2015-10114.

Jiang, Y., N. Li, Q. Wang, Z. Liu, Y. K. Lee, X. Liu, J. Zhao, H. Zhang, and W. Chen. 2020. Microbial diversity and volatile profile of traditional fermented yak milk. J. Dairy Sci. 103:87-97. https:/ /doi.org/10.3168/jds.2019-16753.

Kaditzky, S., and R. F. Vogel. 2008. Optimization of exopolysaccharide yields in sourdoughs fermented by lactobacilli. Eur. Food Res. Technol. 228:291-299. https://doi.org/10.1007/s00217-008-0934-7.

Khorshidian, N., M. Yousefi, and A. M. Mortazavian. 2020. Fermented milk: The most popular probiotic food carrier. Adv. Food Nutr. Res. 94:91-114. https://doi.org/10.1016/bs.afnr.2020.06.007.

Lee, C. S., S. H. Lee, and S. H. Kim. 2020. Bone-protective effects of Lactobacillus plantarum B719-fermented milk product. Int. J. Dairy Technol. 73:706-717. https://doi.org/10.1111/1471-0307 .12701.

Li, T., J. Hu, R. Tian, K. Wang, J. Li, A. Qayum, A. Bilawal, M. A. Gantumur, Z. Jiang, and J. Hou. 2021. Citric acid promotes disulfide bond formation of whey protein isolate in non-acidic aqueous system. Food Chem. 338:127819. https://doi.org/10.1016/j .foodchem.2020.127819.

Li, Y., L. Zhang, and W. Wang. 2013. Heat-induced changes in volatiles of milk and effects of thermal processing on microbial metabolism of yogurt. J. Food Biochem. 37:409-417. https://doi.org/ 10.1111/j.1745-4514.2011.00642.x.

Lopez-Huertas, E. 2010. Health effects of oleic acid and long chain omega-3 fatty acids (EPA and DHA) enriched milks. A review of intervention studies. Pharmacol. Res. 61:200-207. https://doi.org/ 10.1016/j.phrs.2009.10.007.

Mahmood, T., T. Masud, A. Qayyum, A. Mehmood, W. Ahmed, M. Liaquat, M. J. Tareen, S. U. Khan, and S. Ali. 2019. Functional and technological attributes of probiotic yoghurt prepared with Dahi micro-flora during refrigerated storage. Food Sci. Technol. (Campinas) 39:267-273. https://doi.org/10.1590/fst.12317.

Marafon, A. P., A. Sumi, M. R. Alcântara, A. Y. Tamime, and M. Nogueira de Oliveira. 2011. Optimization of the rheological properties of probiotic yoghurts supplemented with milk proteins. Lebensm. Wiss. Technol. 44:511-519. https://doi.org/10.1016/j.lwt .2010 .09 .005 .

Moreno-Montoro, M., M. Navarro-Alarcon, T. Bergillos-Meca, R. Gimenez-Martinez, S. Sanchez-Hernandez, and M. Olalla-Herrera. 2018. Physicochemical, nutritional, and organoleptic characterization of a skimmed goat milk fermented with the probiotic strain Lactobacillus plantarum C4. Nutrients 10:633. https://doi.org/10 $.3390 /$ nu10050633.

Muelas, R., A. Martí de Olives, G. Romero, J. R. Díaz, M. E. SayasBarberá, and E. Sendra. 2018. Evaluation of individual lactic acid bacteria for the fermentation of goat milk: Quality parameters. Lebensm. Wiss. Technol. 98:506-514. https://doi.org/10.1016/j .lwt.2018.09.005.

Nguyen, H. T. H., L. Ong, S. E. Kentish, and S. L. Gras. 2014. The effect of fermentation temperature on the microstructure, physico- chemical and rheological properties of probiotic buffalo yoghurt. Food Bioprocess Technol. 7:2538-2548. https://doi.org/10.1007/ s11947-014-1278-x.

Nyanzi, R., P. J. Jooste, and E. M. Buys. 2021. Invited review: Probiotic yogurt quality criteria, regulatory framework, clinical evidence, and analytical aspects. J. Dairy Sci. 104:1-19. https://doi .org/10.3168/jds.2020-19116.

Oliveira, R. P., A. C. Florence, R. C. Silva, P. Perego, A. Converti, L. A. Gioielli, and M. N. Oliveira. 2009. Effect of different prebiotics on the fermentation kinetics, probiotic survival and fatty acids profiles in nonfat symbiotic fermented milk. Int. J. Food Microbiol. 128:467-472. https://doi.org/10.1016/j.ijfoodmicro.2008.10.012.

Or-Rashid, M. M., N. E. Odongo, B. Subedi, P. Karki, and B. W. McBride. 2008. Fatty acid composition of yak (Bos grunniens) cheese including conjugated linoleic acid and trans-18:1 fatty acids. J. Agric. Food Chem. 56:1654-1660. https://doi.org/10.1021/jf0725225.

Phiri, B. S. J., M. Sakumona, B. M. Hang'ombe, A. Fetsch, and S. Schaarschmidt. 2021. The traditional dairy value chain in Zambia and potential risk factors to microbiological food safety. Food Control 124:107885. https://doi.org/10.1016/j.foodcont.2021.107885.

Rodríguez, R., S. Vargas, F. Quintanilla, A. Trejo, C. Regalado, B. García, and M. González-Torres. 2015. Transformation kinetics during fermented milk production using Lactobacillus johnsonii (La1) and Streptococcus thermophillus: A comparison with yogurt inoculum. Food Biophys. 10:375-384. https://doi.org/10.1007/ s11483-015-9406-3.

Routray, W., and H. N. Mishra. 2011. Scientific and technical aspects of yogurt aroma and taste: A review. Compr. Rev. Food Sci. Food Saf. 10:208-220. https://doi.org/10.1111/j.1541-4337.2011.00151 .x.

Santillo, A., M. Albenzio, M. Quinto, M. Caroprese, R. Marino, and A. Sevi. 2009. Probiotic in lamb rennet paste enhances rennet lipolytic activity, and conjugated linoleic acid and linoleic acid content in Pecorino cheese. J. Dairy Sci. 92:1330-1337. https://doi.org/10 $.3168 /$ jds.2008-1598.

Sieber, R., M. Collomb, A. Aeschlimann, P. Jelen, and H. Ever. 2004. Impact of microbial cultures on conjugated linoleic acid in dairy products - A review. Int. Dairy J. 14:1-15. https://doi.org/10 .1016/S0958-6946(03)00151-1.

Suo, H., X. Zhao, Y. Qian, G. Li, Z. Liu, J. Xie, and J. Li. 2014. Therapeutic effect of activated carbon-induced constipation mice with Lactobacillus fermentum Suo on treatment. Int. J. Mol. Sci 15:21875-21895. https://doi.org/10.3390/ijms151221875.

Tian, H., Y. Shi, Y. Zhang, H. Yu, H. Mu, and C. Chen. 2019. Screening of aroma-producing lactic acid bacteria and their application in improving the aromatic profile of yogurt. J. Food Biochem. 43:e12837. https://doi.org/10.1111/jfbc.12837.

Wu, A. Z., R. W. Lee, B. L. Calvé, and I. Cayeux. 2019. Temporal profiling of simplified lemonade using temporal dominance of sensations and temporal check-all-that-apply. J. Sens. Stud. 34:1-16. https://doi.org/10.1111/joss.12531.

Zhao, L., R. Feng, F. Ren, and X. Mao. 2018. Addition of buttermilk improves the flavor and volatile compound profiles of low-fat yogurt. Lebensm. Wiss. Technol. 98:9-17. https://doi.org/10.1016/j .lwt.2018.08.029.

Zhou, T., R. Huo, L. Y. Kwok, C. Li, Y. Ma, Z. Mi, and Y. Chen. 2019. Effects of applying Lactobacillus helveticus H9 as adjunct starter culture in yogurt fermentation and storage. J. Dairy Sci. 102:223-235. https://doi.org/10.3168/jds.2018-14602. 